\title{
Hyaluronic acid: a versatile biomaterial in tissue engineering
}

\author{
Zhu Zhu, Yin-Min Wang, Jun Yang, Xu-Song Luo \\ Department of Plastic and Reconstructive Surgery, Shanghai Ninth People's Hospital, Shanghai Jiao Tong University School of Medicine, Shanghai \\ 200011, China. \\ Correspondence to: Dr. Xu-Song Luo, Department of Plastic and Reconstructive Surgery, Shanghai Ninth People's Hospital, Shanghai Jiao Tong \\ University School of Medicine, No. 639, Zhizaoju Road, Shanghai 200011, China. E-mail: luoxs71@126.com
}

How to cite this article: Zhu Z, Wang YM, Yang J, Luo XS. Hyaluronic acid: a versatile biomaterial in tissue engineering. Plast Aesthet Res 2017;4:21927.

\author{
Article history: \\ Received: 28 Sep 2017 \\ First Decision: 1 Dec 2017 \\ Revised: 8 Dec 2017 \\ Accepted: 8 Dec 2017 \\ Published: 29 Dec 2017
}

Keywords:

Hyaluronic acid,

biomaterials,

tissue engineering and

regenerative medicine,

stem cells

\begin{abstract}
The design and application of hyaluronic acid (HA)-based scaffolds to control cell response and construct ideal tissue engineering products have been of great interest in the past few decades. This review provides an overview of the biological properties of HA to better understand how to engineer a cell-scaffold composite that is qualified in tissue engineering; important tissue engineering applications of HA including cartilage tissue engineering; and lastly, the problems of the current research on HA. All the data described above were collected and analyzed from PubMed, EMBASE and Medline.
\end{abstract}

\section{INTRODUCTION}

Hyaluronic acid or hyaluronan (HA) was the first isolated from bovine vitreous humor by Meyer and Palmer ${ }^{[1]}$ in 1934. It was named because of its transparent appearance in water and the probable presence of hexuronic acid as one of the components. HA is a linear polysaccharide without branches and is one of the most important components of extracellular matrix. Researches demonstrated that HA plays an important role in regulating cell differentiation, migration, angiogenesis and inflammation responses ${ }^{[2-5]}$. HA has become a hotspot in the fields of scaffold materials in tissue engineering because of its ubiquitously distribution in vertebrate tissues, good biocompatibility and non-toxic degradation products. The versatility of $\mathrm{HA}$ is closely related to its unique properties, andHA with its different states or molecular weights can exhibitdiverse features. Therefore, to understand the application of HA, the basic physical, chemical and biological properties of HA must first be understood.

A review of the literature was performed by searching the keywords "hyaluronic acid" AND "tissue

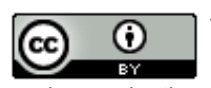

\section{Lice}

and reproduction ir

For reprints contact: service@oaepublish.com

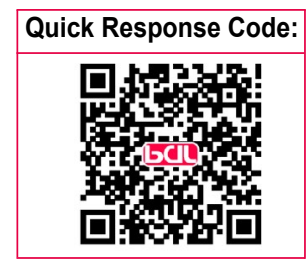

C) The Author(s) 2017 


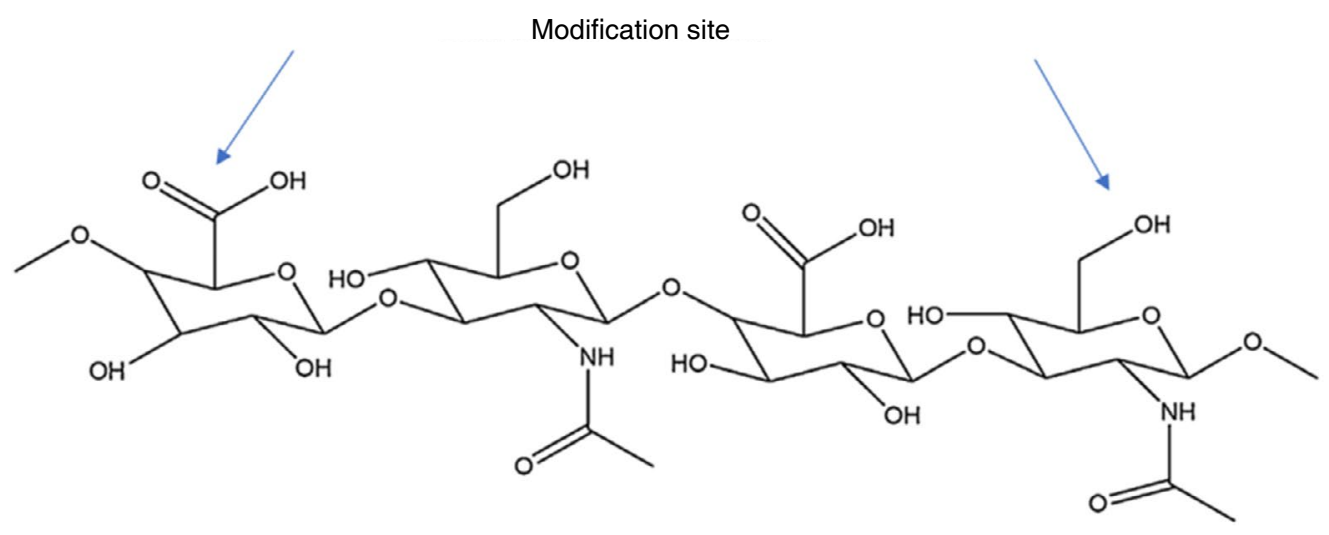

Figure 1: Molecular formula of hyaluronic acid disaccharide unit

engineering" OR "tissue regeneration" OR "stem cells" in PubMed, EMBASE and Medline. The most important or typical papers discussing cartilage and bone tissue engineering using HA-based scaffolds were viewed and selectively cited. Skin and soft tissue engineering with $\mathrm{HA}$-based scaffold were reviewed as well.

\section{THE PHYSICAL, CHEMICAL AND BIOLOGICAL PROPERTIES OF HA}

$\mathrm{HA}$ is an unbranched non-sulfated glycosaminoglycan composed of repeating disaccharides $[\beta-1,4-D$ glucuronic acid (known as uronic acid) and $\beta-1,3-\mathrm{N}$ acetyl-D-glucosamide] [Figure 1$]^{[6]}$. Since HA is rich in carboxyl and hydroxyl groups, it can form a hydrogel under mild conditions like chemical modification, crosslinking or photo-crosslinking. The mechanical strength, physical and chemical properties of the materials depend on the degree of the modification and crosslinking ${ }^{[1,7]}$. The physical properties of HA include its compressive stress, compressive modulus, storage and loss modulus, porosity, swelling rate, degradation rate and density ${ }^{[8]}$.

\section{The physical property of HA}

$\mathrm{HA}$ has a molecular weight between $10^{3}$ and $10^{4} \mathrm{kDa}$, which can reach a length of $25 \mu \mathrm{m}$ when fully extended ${ }^{[9,10]}$. The high hydrophilicity of HA is the physical basis for its wide presence in the human body. The molecular chains of HA are intertwined in solution and it occurs even when the concentration is very low. This phenomenon can be observed in HA solution as low as $1 \mathrm{mg} / \mathrm{mL}$, which is one of the reasons to the unique rheological characteristics of HA [Figure 2] ${ }^{[11]}$. In human bodies, especially soft tissues, HA often exists in the form of high molecular weights which is the essential reason for its high viscosity even in diluted solutions. Moreover, the mutual macromolecular crowding in human body contributes to the higher viscosity ${ }^{[12]}$. With macromereconcentrations from 2 to $20 \mathrm{wt} \%$, networks exhibited volumetric swelling ratios ranging from $\sim 42$ to 8 , compressive moduli ranging from $\sim 2$ to over $100 \mathrm{kPa}$, and degradation times ranging from less than 1 day up to almost 38 days in the presence of $100 \mathrm{U} / \mathrm{mL}$ of hyaluronidase. Although higher molecular weight or crosslinking degree can result in improved compressive modulus that is essential in the tissue engineering of cartilage or bone, the viability of seed cells would be compromised ${ }^{[13]}$. In most instances, HA exhibited a highly porous morphology so that cells can permeate into the scaffold easily. Under most circumstances, the HA macromere is degraded by hyaluronidase. However, it can also be degraded by reducing substances or at acidic $\mathrm{pH}$ values after modification $^{[14]}$.

\section{The chemical property of HA}

The characteristics of HA including its consistency, biocompatibility, hydrophilicity, limited immunogenicity and unique viscoelasticity have made it an excellent moisturizer in cosmetic dermatology and skin-care products as well as a potential biomaterial in tissue engineering. However, HA without modification tends to be absorbed rapidly in human body, which makes it unqualified in tissue engineering. To overcome this defect, chemical modification is indispensable. Many biomaterials do not have a lot of chemically modified sites, while HA can be chemically modified with its hydroxyl, carboxyl and $\mathrm{N}$-acetylaminoends ${ }^{[15]}$. The chemical modification of HA can be roughly divided into two types: esterification and crosslinking. The purpose of esterification is to link HA with certain hydrophobic groups, reducing the poly anion properties of HA. Under certain conditions, the carboxyl group of HA can undergo esterification reaction to produce HYAFF, an esterified derivative of $\mathrm{HA}^{[16]}$. In this reaction, many different alcohols, such as fatty 


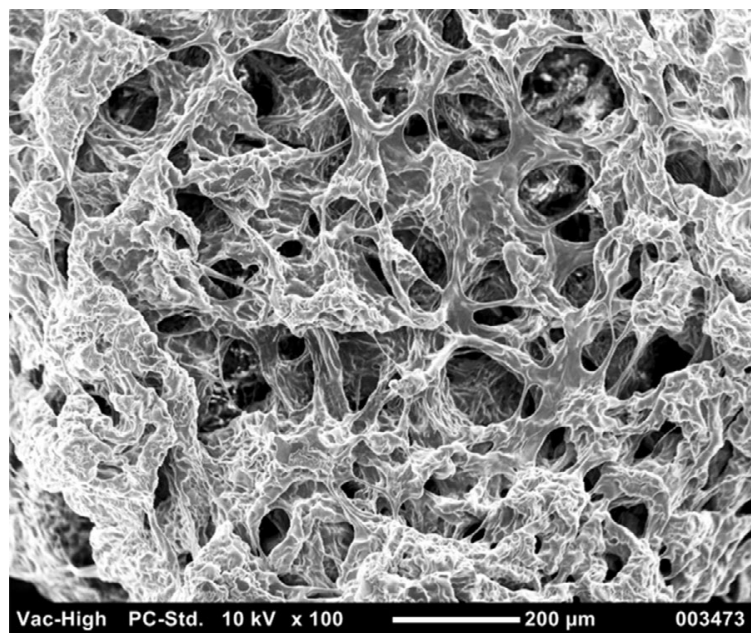

Figure 2: The morphology of hyaluronic acid (RESTYLANE ${ }^{\circledR}$ ) using scanning electron microscopy

alcohols and aryl fatty alcohols can be bound to HA moleculesin order to improve the chemical properties of $\mathrm{HA}$ and its stability as a tissue engineering scaffold, as well as to extend its maintenance in the human body. The purpose of HA cross-linking is to convert it from solid state to hydrogel state under mild conditions and to prolong its maintaining time in the human body ${ }^{[17]}$. Besides, the mechanical strength of crosslinked HA can be remarkably improved compared to the noncrosslinked one, which makes it more suitable for tissue engineering applications.

The cross-linking reaction of $\mathrm{HA}$ can be divided into complete or incomplete one. The complete cross-linking reaction causes the HA molecules to be covalently attached to the continuous polymer network so that $\mathrm{HA}$ is no longer soluble in the water. While the incomplete reaction prompts part of the covalent binding reactions of HA molecules, resulting in partial solubility after the reaction. 1-ethyl-3-(3dimethylaminopropyl) carbodiimide, divinyl sulfone, glutaraldehyde, butanediol-diglycidyl ether are the most common crosslinking agents [Figure 3$]^{[18]}$.

\section{The biological property of HA}

HA is synthesized by HA synthesis (HAS) on the cell membrane. And it is the only glycosaminoglycan that is not synthesized in the Golgisome. There are three different HAS in mammals, HAS1, HAS2 and HAS3. The three enzymes are located on different chromosomes, producing HA with different molecular weights ${ }^{[11]}$. The expression of HAS isoenzymes varies under different status of morphogenesis and pathology. For example, HA in infants is of abundant quantity, however, in the process of growing up it is gradually replaced by collagen fibers and proteolycins which accounts for the fact that mature tissue can

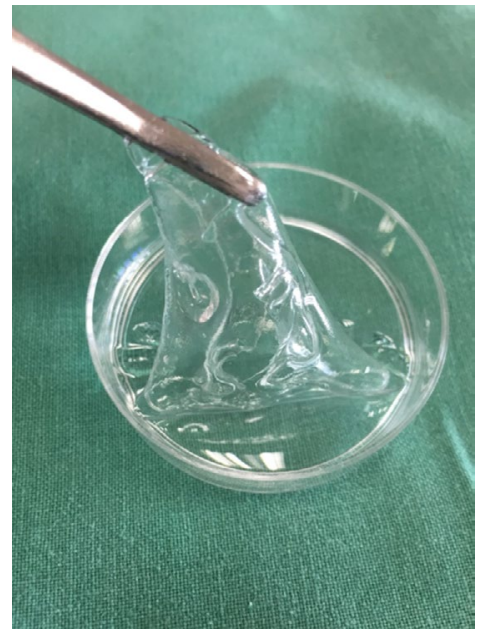

Figure 3: The gross view of cross-linked hyaluronic acid using BDDE at the concentration of $0.8 \%$

withstand greater mechanical force ${ }^{[19]}$.

It is almost certain that most kinds of vertebrate cells synthesize HA at some point in their natural history. When fibroblasts, mesothelial or certain other kinds of cell are plated out in tissue culture, they surround themselves in a few hours with a transparent gel-like HA which can protect themselves against damage by immune cells, impedes virus infection and may be important in mitosis ${ }^{[19]}$.

\section{CELL-MATRIX INTERACTIONS IN HA HYDROGEL SCAFFOLDS}

At present, different origins derived stem cells are the most universally used seed cells in tissue engineering. HA can interact with many stem cell surface receptors, inducing intracellular signal transduction through the connection with these receptors and activating corresponding proteins in a direct or indirect pattern ${ }^{[20]}$.

Through signal transduction receptors, HA can affect the most essential cell activities including proliferation, survival, movement and differentiation. One of the most important receptors is CD44, which provides an agent for maintaining and anchoring the proteoglycan polymer to the cytoplasmic membrane. CD44 plays an important role in tissue formation by mediating the remodeling of extracellular matrix, intercellular interactions, and cell-matrix interactions ${ }^{[21]}$. In addition, the close connection with the cytoskeleton allows CD44 to induce intracellular signal transduction, thereby experiencing changes in the extracellular matrix environment and triggering cellular responses ${ }^{[22]}$. Besides, CD44 receptors are of widespread concern because they are essential to 
maintain cartilage phenotype and $\mathrm{HA}$ catabolism ${ }^{[5]}$. $\mathrm{HA}$-containing materials can also interact with proteins or cells through the receptor for hyaluron-mediated motility or intercellular adhesion molecule-1.

There are also some reports that HA-based scaffolds can directly induce or promote stem cell differentiation ${ }^{[22]}$. In vitro experiments conducted by Meng et al. ${ }^{[23]}$ demonstrated that HA-based scaffold can induce stem cells into cartilage in basal medium without the addition of growth factors. The increased expression of an important HA receptor like CD44, also suggested the interaction of cells with $\mathrm{HA}^{[24]}$. In addition, Choi et al. ${ }^{[25]}$ reported that HA oligomers in the skin substitute models could promote the survival of basal stem cells. Their experiments demonstrated that a recognized skin stem cell marker p63 expression was elevated in the skin substitute model added HA oligomer (400-2000 Da), therefore, HA may also help to maintain stemness ${ }^{[25]}$. Huang et al. ${ }^{[26]}$ also reported that mesenchymal stem cells grown on chitosan-HA membranes performed better in maintaining stemness markers (Oct4, Sox2 and Nanog) than cells cultured on common dishes. On the contrary, if CD44 was blocked by the antibody, then the cells would lose their ability to maintain the spherical form while the stemness gene expression would also decline. It indicated that HA may assist in maintaining stemness through $\mathrm{CD} 44^{[26]}$.

\section{HAIN TISSUE ENGINEERING}

Tissue transplantation is one of the most frequent and most important treatments in plastic and reconstructive surgery. However, autologous transplantation is often limited by the insufficiency and trauma of donor site, while allogeneic transplantation is faced with immune rejection, donor scarcity, transplant infection and other risks. The emergence of tissue engineering is a promising technique to overcome these problems above.

Tissues or even organs can be regenerated by the coordination of seed cells, scaffold and growth factors. The histocompatibility, chemical modification and biodegradability of HA make it an ideal scaffold for tissue engineering. The properties of hydrogel can mimic the water content of human tissue and contribute to the exchange of oxygen, nutrition and metabolic waste ${ }^{[27,28]}$. In addition, the fluid morphology makes it possible to inject the scaffold through a tiny needle hole, which can greatly reduce the trauma and infection rate of the operation. Therefore, it has been one of the hotspots in tissue engineering materials and used in a variety of fields. The ideal tissue engineering scaffold should have good cell adhesion to support the growth of seed cells, however, HA tends to have weak cell adhesion. Therefore, modifications like heparin decorated, Arg-Gly-Asp (RGD) sequence linking are indispensable ${ }^{[29-31]}$.

\section{HA in vascular tissue engineering}

In tissue engineering construction, a scaffold has to maintain its structure for several months or longer before extracellular matrix is deposited. Since the diffusion of nutrients and essential gases to cells is typically limited to a depth of $150-250 \mu \mathrm{m}$ from a capillary (3-10 cells thick ${ }^{[32]}$, tissue constructs must permit in-growth of a blood capillary network to nourish and sustain the viability of cells within ${ }^{[4]}$. HA can be chemically modified to promote angiogenesis without changing its original biocompatibility or weak immunogenicity ${ }^{[33]}$. HA can be degraded into oligomers (HA oligomers, HAO) (4-25 dose units) by hyaluronidase in vivo. These HAOs have a high biological activity and are capable of affecting cell behavior including angiogenesis through monovalent bond to the host cells ${ }^{[3,34]}$. Silva et al. ${ }^{[2]}$ demonstrated that gellan gum-HA hydrogel can be degraded by hyaluronidase and release various amounts and sizes of HA oligomers that are capable of promoting the proliferation of human umbilical vein endothelial cells.Besides, in the mice hind limb ischemia model, HA-cell composite can significantly promote angiogenesis. A series of in vitro and in vivo experiments have shown that long-chain (native high molecular weight) HA at physiological concentrations has the ability to resist inflammation and inhibit angiogenesis. Long-chain HA can bind to CD44, and inhibit cell proliferation, cell cycle in the key signal transduction, thereby inhibiting angiogenesis. While $\mathrm{HAO}$ will compete with long-chain $\mathrm{HA}$ for binding to CD44 and prompt mitosis and angiogenesis ${ }^{[35]}$. The CD44-HA oligosaccharide interactions that primarily cause these pro-mitotic effects have also been shown to stimulate matrix metalloproteinase-2 and -9 production and thereby increase cell invasion through extracellular matrix barriers to facilitate vessel sprouting and outgrowth ${ }^{[36]}$. Since the pro-angiogenic HA oligomers cannot by themselves be crosslinked to yield solid biomaterials, and can also potentially incite inflammatory/activated cell responses, they must be presented on other scaffolding biomaterials, either synthetic or natural ${ }^{[37,38]}$. Another method is to mix with the more bioinert long-chain HA in such a manner as to fulfill the physical and mechanical requirements of the biomaterial, elicit the desired biologic responses, and yet deter excessive and long-term inflammation ${ }^{[4]}$. 


\section{HA in cartilage tissue engineering}

In the application of HA-based materials, cartilage tissue engineering is the most extensive due to the fact that HA is quite a suitable scaffold for the growth of chondrocyte. The extracellular matrix of chondrocytes is rich in glucosamine and HA while the latter one plays an important role in regulating the function of chondrocyte ${ }^{[39]}$. Moreover, since HA can also be used as a scaffold in bone regeneration ${ }^{[40]}$, it is a suitable material for osteochondral tissue engineering ${ }^{[41,42]}$. HA, as a scaffold, has several possible mechanisms to promote cartilage formation. First, HA can induce stem cells, cartilage progenitor cells to differentiate into chondrocytes. Some papers indicate that HA involves in the maintenance of chondrocyte phenotype, which is utmost important for the reason that chondrocyte can lose its phenotype during in vitro culture ${ }^{[43]}$. Furthermore, $\mathrm{HA}$ is favorable to the deposition of extracellular matrix which is essential in cartilage tissue engineering ${ }^{[44-48]}$. Besides, HA-containing hydrogel material has a lower oxygen concentration, while the hypoxic environment is conducive to the growth of chondrocytes ${ }^{[48]}$. Another possible mechanism is that HA interacts with cells through the cell surface of the CD44 receptor, regulating cell migration, proliferation, differentiation, and other close contact with the cytoskeleton to CD44-activated cells within the signal transduction ${ }^{[49]}$. HA binds to proteoglycans by the aid of core proteins. These proteoglycan monomers can connect with CD44 receptors on chondrocytes, while the released ones in the extracellular matrix can enhance matrix permeability, therefore improve the stress resistances ${ }^{[39]}$. Lammi et al. ${ }^{[50]}$ reported that HA deposition would occur in the areas of cartilage injury and it would attract exogenous mesenchymal stem cells to the injured area. HA can also act as a cell carrier, wrapping stem cells and chondrocytes in the injected area so that the cells can proliferate and differentiate in situ ${ }^{[45,51]}$. Chung and Burdick ${ }^{[52]}$ demonstrated in both in vivo and in vitro experiments that methacrylated HA is capable of providing a microenvironment that facilitates differentiation of mesenchymal stem cells into cartilage, and the effect can be enhanced in the presence of certain cytokines such as transforming growth factor- $\beta 3$.

Methacrylated HA is gaining increasingly attention because it can gelatinize through an easy photocrosslinking, moreover, seed cells can be encapsulated into HA in this way which enables the cell to live in a $3 D$ environment ${ }^{[52,53]}$. Conventional cartilage tissue engineering materials requirea much larger incision than injectable ones, andphotocrosslinkingHA can transform from liquid to hydrogel through ultraviolet irradiation after injected into the ideal site and fill the defect space with various shapes. Chung and Burdick ${ }^{[52]}$ used methacrylated HA with human multipotent stromal cells (MSCs) to regenerate cartilage, and they demonstrated that both in vitro and in vivo cultures of MSC-laden HA hydrogels permitted chondrogenesis, measured by the early gene expression and production of cartilage specific matrix proteins. This kind of in situ cross-linking ways including photo-crosslinking and thermosensitive crosslinking will be a possible future trend.

Besides served as a scaffold, HA can also be used a biologically active molecule to modify bio-inert artificial materials such as polyethylene glycol (PEG), small intestinal submucosa, etc. ${ }^{[54]}$. The HA-based cellscaffold composite can provide a framework for the regenerated matrix. Skaalure et al. ${ }^{[51]}$ demonstrated that biodegradable PEG hydrogel modified by high concentration of HA can evidently improve the deposition of extracellular matrix and proliferation of chondrocytes.

HA is most generally used in the cross-linked, modifiedform or as composite with other materials such as platelet-rich plasma ${ }^{[55]}$, fibrin ${ }^{[46]}$, chitosan ${ }^{[45]}$, tricalcium phosphate, collagen ${ }^{[48]}$, alginate, etc. This is because the cross-linked HA has better mechanical properties than the linear one, while the composite material can combine the advantages of different materials, corresponding with the requirements of tissue engineering scaffold materials ${ }^{[22]}$. Chen et al. ${ }^{[55]}$ demonstrated that $\mathrm{HA}$ and platelet-rich plasma can restore the down-regulation of cartilage gene expression induced by interleukin- $1 \beta$ and tumor necrosis factor- $\alpha$, including SOX-9, collagen type II and aggrecan.

In addition, there have been reports of using $\mathrm{HA}$ as scaffold in the engineering of intervertebral disk ${ }^{[56]}$, vocal cords ${ }^{[57]}$, nucleus pulposus ${ }^{[58]}$, etc.

\section{$\mathrm{HA}$ in bone tissue engineering}

$\mathrm{HA}$ also has a wide range of research and application in bone tissue engineering, it can be used as a scaffold or molecular carrier to promote bone tissue regeneration ${ }^{[40,59]}$. The existing papers show that its application has been explored in the field of skull ${ }^{[60]}$, alveolar ${ }^{[61]}$ and so on. As in cartilage tissue engineering, $\mathrm{HA}$ is also usually required for modification in bone tissue engineering. Since the mechanical properties of $\mathrm{HA}$ are weaker than that of human natural bones, the use of $\mathrm{HA}$ alone as a scaffold material is not sufficient to support the cellscaffold composite and requires other materials to 
be compounded. For example, Subramaniam et al. ${ }^{[61]}$ demonstrated that $\mathrm{HA}$ can be compounded with hydroxyapatite (one of the components of the bone matrix) and modified with calcium sulfate, which encapsulates collagenase. The composite above can serve as a substitute for alveolar bone to produce satisfactory outcomes.

HA can regulate cell differentiation and bone formation by binding to CD44, CD168 on seed cells, such as mesenchymal cells ${ }^{[62]}$. Zhu et al. ${ }^{[63]}$ demonstrated that $\mathrm{N}$-cadherin modified $\mathrm{HA}$ can promote the differentiation of human mesenchymal cells into bone, leading to more bone matrix deposition. $\mathrm{N}$-cadherin is an important factor in mediating cell-cell interactions during the cluster of mesenchymal cells in bone formation $^{[64]}$. In the experiment, they also modified HA with RGD peptide because only the calcium cadherin was sufficient to provide sufficient cell adhesion.

As a molecular carrier, $\mathrm{HA}$ has a wide range of applications on the in vivo experiments. Of all the researches, carrying bone morphogenetic protein 2 (BMP-2) to promote bone formation, fracture healing is the most commonly used method. BMP-2 is a potent bone-forming molecule that has been approved by the Food and Drug Administration for intervertebral fusion, open tibial fractures, and alveolar bone expansion ${ }^{[65]}$. Bhakta et al. ${ }^{[6]}$ confirmed that the thiolated-HA exhibited a low burst followed by a sustained release of BMP-2 while collagen sponge rapidly released BMP-2 with a high burst phase that was followed by a low sustained phase. Analysis of bone formation by micro-computed tomography revealed that low burst followed by sustained release of BMP-2 from a HA hydrogel induced up to $456 \%$ more bone compared to a BMP-2 dose-matched collagen sponge that has a high burst and sustained release. Bhakta et al. ${ }^{[67]}$ also reported that heparin-modified HA also had a similar controlled release effect.

\section{HA in skin and soft tissue engineering}

Tissue engineering skin equivalents (substitutes) is one of the most successful and most widely used products in tissue engineering so far. It is usually manufactured by seeding keratinocytes and fibroblasts into non-human (e.g. type I bovine collagen) matrix ${ }^{[68]}$. However, this tissue engineering skin can only last for approximate 8 weeks due to its high shrinkage of the extracellular matrix, which is not sufficient to form a normal human extracellular matrix consisting of fat, fibrin, glycosaminoglycans and polysaccharides ${ }^{[68]}$. Stark et al. ${ }^{[69]}$ seeded keratinocytes on esterified HA fibers, producing the dermal equivalents that could last for a longer period and was more similar to normal skin tissue.

In addition to tissue engineering of skin substitute, HA has also been used to increase the retention rate of fat grafts. Alghoul et al. ${ }^{[70]}$ used HA as a cell carrier, mixing with autologous fat of the same volume and transplanted into the back of a nude mouse. They found that HA can improve the survival rate of early fat transplantation and prolong the fat maintenance time.

\section{DISCUSSION}

Tissue engineering is one of the most promising methods in wound healing, while $\mathrm{HA}$ is one of the most suitable natural materials in hydrogel scaffolds. HA has similar water content as human tissue, has good tissue compatibility, and it plays an important role in promoting the proliferation and differentiation of seed cells. In addition, high molecular weight $\mathrm{HA}$ has a certain anti-inflammatory effect, and low molecular weight HA oligomers have been shown to promote angiogenesis. At present, $\mathrm{HA}$ as a scaffold material, connecting molecules, carrier of drugs and other small molecules has been widely used in tissue engineering. Since the microenvironment formed by HA is particularly suitable for the growth of chondrocytes, the application of HA in cartilage tissue engineering is the most popular. Researchers have also devoted themselves to the regeneration of bone tissues, myocardial tissues, skin and soft tissues with the utilization of HA. Natural HA has a short reservation time in vivo due to the rapid degradation by hyaluronidase, therefore appropriate cross-linking and modification of the active group is essential. HA after cross-linking and modification has been widely used alone or compounded with other materials in the tissue engineering. Since HA itself doesn't have a satisfying cell adhesion, modification with RGD sequence or heparincan be considered as anecessary improvement.

The current problem is that there are a variety of cross-linking and modification methods of HA. Moreover, the raw materials from different origins owning divergent molecular weight (ranging from hundreds to millions), thus exhibiting different biological properties, which brings about quite a lot of difficulties to the research and application of HA. Since the high cross-linking (high molecular weight) and low cross-linking (low molecular weight) HA make such a great difference in the biological properties that how to combine the anti-enzymatic ability of high molecular weight HA with the high biological activity of low molecular weight HA remains to be explored. 


\section{DECLARATIONS}

\author{
Authors' contributions \\ Data collection and analysis: Z. Zhu, Y.M. Wang \\ Manuscript preparation: Z. Zhu, X.S. Luo \\ Manuscript's review: J. Yang \\ Concept design, manuscript preparation and data \\ interpretation: X.S. Luo
}

\section{Financial support and sponsorship \\ None.}

\section{Conflicts of interest \\ There are no conflicts of interest.}

\section{Patient consent \\ Not applicable.}

\section{Ethics approval Not applicable.}

\section{REFERENCES}

1. Meyer K, Palmer JW. The polysaccharide of the vitreous humor. $J$ Biol Chem 1934;107:629-34.

2. Silva LP, Pirraco RP, Santos TC, Novoa-Carballal R, Cerqueira MT, Reis RL, Correlo VM, Marques AP. Neovascularization induced by the hyaluronic acid-based spongy-like hydrogels degradation products. ACS Appl Mater Interfaces 2016;8:33464-74

3. Rooney P, Kumar S, Ponting J, Wang M. The role of hyaluronan in tumour neovascularization (review). Int J Cancer 1995;60:632-6.

4. Pardue EL, Ibrahim S, Ramamurthi A. Role of hyaluronan in angiogenesis and its utility to angiogenic tissue engineering. Organogenesis 2008;4:203-14.

5. Kota DJ, Prabhakara KS, Cox CS, Olson SD. MSCs and hyaluronan: sticking together for new therapeutic potential? Int J Biochem Cell Biol 2014;55:1-10.

6. Fakhari A, Berkland C. Applications and emerging trends of hyaluronic acid in tissue engineering, as a dermal filler, and in osteoarthritis treatment. Acta Biomater 2013;9:7081-92.

7. Tan H, Marra KG. Injectable, Biodegradable hydrogels for tissue engineering applications. Materials 2010;3:1746-67.

8. Collins MN, Birkinshaw C. Hyaluronic acid based scaffolds for tissue engineering--a review. Carbohydr Polym 2013;92:1262-79.

9. Kogan G, Soltes L, Stern R, Gemeiner P. Hyaluronic acid: a natural biopolymer with a broad range of biomedical and industrial applications. Biotechnol Lett 2007;29:17-25.

10. Laurent TC, Laurent UB, Fraser JR. Functions of hyaluronan. Ann Rheum Dis 1995;54:429-32.

11. Lee JY, Spicer AP. Hyaluronan: a multifunctional, megaDalton, stealth molecule. Curr Opin Cell Biol 2000;12:581-6.

12. Cowman MK, Schmidt TA, Raghavan P, Stecco A. Viscoelastic properties of hyaluronan in physiological conditions. F1000Res 2015;4:622.

13. Burdick JA, Chung C, Jia X, Randolph MA, Langer R. Controlled degradation and mechanical behavior of photopolymerized hyaluronic acid networks. Biomacromolecules 2005;6:386-91.

14. Cui N, Qian J, Liu T, Zhao N, Wang H. Hyaluronic acid hydrogel scaffolds with a triple degradation behavior for bone tissue engineering. Carbohydr Polym 2015;126:192-8.

15. Laurent TC. The Chemistry, Biology and Medical Applications of Hyaluronan and Its Derivatives. Portland: Portland Pr; 1998.

16. Aigner J, Tegeler J, Hutzler P, Campoccia D, Pavesio A, Hammer C, Kastenbauer E, Naumann A. Cartilage tissue engineering with novel nonwoven structured biomaterial based on hyaluronic acid benzyl ester. J Biom Mater Res 1998;42:172-81.

17. Segura T, Anderson BC, Chung PH, Webber RE, Shull KR, Shea LD Crosslinked hyaluronic acid hydrogels: a strategy to functionalize and pattern. Biomaterials 2005;26:359-71.

18. Collins MN, Birkinshaw C. Comparison of the effectiveness of four different crosslinking agents with hyaluronic acid hydrogel films for tissue-culture applications. J Appl Polym Sci 2010;104:3183-91.

19. Fraser JR, Laurent TC, Laurent UB. Hyaluronan: its nature, distribution, functions and turnover. J Intern Med 1997;242:27-33.

20. Kim Y, Lee YS, Choe J, Lee H, Kim YM, Jeoung D. CD44-epidermal growth factor receptor interaction mediates hyaluronic acid-promoted cell motility by activating protein kinase $\mathrm{C}$ signaling involving Akt, Rac1, Phox, reactive oxygen species, focal adhesion kinase, and MMP-2. J Biol Chem 2008;283:22513-28.

21. Knudson CB. Hyaluronan and CD44: strategic players for cell-matrix interactions during chondrogenesis and matrix assembly. Birth Defects Res Part C Embryo Today 2003;69:174-96.

22. Prè ED, Conti G, Sbarbati A. Hyaluronic acid (HA) scaffolds and multipotent stromal cells (MSCs) in regenerative medicine. Stem Cell Rev 2016;12:664-81.

23. Meng F, He A, Zhang Z, Zhang Z, Lin Z, Yang Z, Long Y, Wu G, Kang Y, Liao W. Chondrogenic differentiation of ATDC5 and hMSCs could be induced by a novel scaffold-tricalcium phosphate-collagenhyaluronan without any exogenous growth factors in vitro. $J$ Biomed Mater Res A 2014;102:2725-35.

24. Cristino S, Grassi F, Toneguzzi S, Piacentini A, Grigolo B, Santi S, Riccio M, Tognana E, Facchini A, Lisignoli G. Analysis of mesenchymal stem cells grown on a three-dimensional HYAFF $11 \circledR$-based prototype ligament scaffold. J Biomed Mater Res A 2005;73:275-83.

25. Choi HR, Kang YA, Na JI, Huh SY, Huh CH, Kim KH, Park KC. Oligosaccharides of hyaluronic acid increased epidermal cell stemness by modulation of integrin expression. J Cosmet Dermatol 2012;11:290-6.

26. Huang GS, Dai LG, Yen BL, Hsu SH. Spheroid formation of mesenchymal stem cells on chitosan and chitosan-hyaluronan membranes. Biomaterials 2011;32:6929-45.

27. Li L. Recent advances of biomaterials in biotherapy. Regen Biomater 2016;3:99-105.

28. Hunt NC, Grover LM. Cell encapsulation using biopolymer gels for regenerative medicine. Biotechnol Lett 2010;32:733-42.

29. Xu X, Jha AK, Duncan RL, Jia X. Heparin-decorated, hyaluronic acid-based hydrogel particles for the controlled release of bone morphogenetic protein 2. Acta Biomater 2011;7:3050-9.

30. Chua PH, Neoh KG, Kang ET, Wang W. Surface functionalization of titanium with hyaluronic acid/chitosan polyelectrolyte multilayers and RGD for promoting osteoblast functions and inhibiting bacterial adhesion. Biomaterials 2008;29:1412-21.

31. Cui FZ, Tian WM, Hou SP, Xu QY, Lee IS. Hyaluronic acid hydrogel immobilized with RGD peptides for brain tissue engineering. J Mater Sci Mater Med 2006;17:1393-401

32. Colton CK. Implantable biohybrid artificial organs. Cell Transplant 1995;4:415-36.

33. Perng $\mathrm{CK}$, Wang $\mathrm{YJ}$, Tsi $\mathrm{CH}, \mathrm{Ma} \mathrm{H}$. In vivo angiogenesis effect of porous collagen scaffold with hyaluronic acid oligosaccharides. $J$ Surg Res 2011;168:9-15.

34. West DC, Hampson IN, Arnold F, Kumar S. Angiogenesis induced by degradation products of hyaluronic acid. Science 1985;228:1324-6. 
35. Park D, Kim Y, Kim H, Kim K, Lee YS, Choe J, Hahn JH, Lee H, Jeon J, Choi C, Kim YM, Jeoung D. Hyaluronic acid promotes angiogenesis by inducing RHAMM-TGF $\beta$ receptor interaction via CD44-PKCס. Mol Cells 2012;33:563-74.

36. Ohno-Nakahara M, Honda K, Tanimoto K, Tanaka N, Doi T, Suzuki A, Yoneno K, Nakatani Y, Ueki M, Ohno S, Knudson W, Knudson CB, Tanne K. Induction of CD44 and MMP expression by hyaluronidase treatment of articular chondrocytes. J Biochem 2004;135:567-75.

37. Mohandas A, Anisha BS, Chennazhi KP, Jayakumar R. Chitosanhyaluronic acid/VEGF loaded fibrin nanoparticles composite sponges for enhancing angiogenesis in wounds. Colloids Surf B Biointerfaces 2015;127:105-13.

38. Seidlits SK, Drinnan CT, Petersen RR, Shear JB, Suggs LJ, Schmidt CE. Fibronectin-hyaluronic acid composite hydrogels for threedimensional endothelial cell culture. Acta Biomater 2011;7:2401-9.

39. Carney SL, Muir H. The structure and function of cartilage proteoglycans. Physiol Rev 1988;68:858-910.

40. Kim J, Kim IS, Cho TH, Lee KB, Hwang SJ, Tae G, Noh I, Lee $\mathrm{SH}$, Park Y, Sun K. Bone regeneration using hyaluronic acid-based hydrogel with bone morphogenic protein-2 and human mesenchymal stem cells. Biomaterials 2007;28:1830-7.

41. Kayakabe M, Tsutsumi S, Watanabe H, Kato Y, Takagishi K. Transplantation of autologous rabbit BM-derived mesenchymal stromal cells embedded in hyaluronic acid gel sponge into osteochondral defects of the knee. Cytotherapy 2006;8:343-53.

42. Park JY, Choi JC, Shim JH, Lee JS, Park H, Kim SW, Doh J, Cho DW. A comparative study on collagen type I and hyaluronic acid dependent cell behavior for osteochondral tissue bioprinting. Biofabrication 2014;6:035004.

43. Kim DH, Martin JT, Elliott DM, Smith LJ, Mauck RL. Phenotypic stability, matrix elaboration and functional maturation of nucleus pulposus cells encapsulated in photocrosslinkable hyaluronic acid hydrogels. Acta Biomater 2015;12:21-9.

44. Hwang HD, Cho HJ, Balakrishnan P, Chung CW, Yoon IS, Oh YK, Byun Y, Kim DD. Cross-linked hyaluronic acid-based flexible cell delivery system: application for chondrogenic differentiation. Colloids Surf B Biointerfaces 2011;91:106-13.

45. Park H, Choi B, Hu J, Lee M. Injectable chitosan hyaluronic acid hydrogels for cartilage tissue engineering. Acta Biomater 2013;9:4779-86.

46. Yu Y, Brouillette MJ,Seol D, Zheng H, Buckwalter JA, Martin JA. Use of recombinant human stromal cell-derived factor $1 \alpha$-loaded fibrin/hyaluronic acid hydrogel networks to achieve functional repair of full-thickness bovine articular cartilage via homing of chondrogenic progenitor cells. Arthritis Rheumatol 2015;67:1274-85.

47. Toh WS, Lim TC, Kurisawa M, Spector M. Modulation of mesenchymal stem cell chondrogenesis in a tunable hyaluronic acid hydrogel microenvironment. Biomaterials 2012;33:3835-45.

48. Amann E, Wolff P, Breel E, van Griensven M, Balmayor ER. Hyaluronic acid facilitates chondrogenesis and matrix deposition of human adipose derived mesenchymal stem cells and human chondrocytes co-cultures. Acta Biomater 2017;52:130-44.

49. Cai Y, Lópezruiz E, Wengel J, Creemers LB, Howard KA. A hyaluronic acid-based hydrogel enabling CD44-mediated chondrocyte binding and gapmer oligonucleotide release for modulation of gene expression in osteoarthritis. J Control Release 2017;253:153-9.

50. Lammi PE, Lammi MJ, Tammi RH, Helminen HJ, Espanha MM. Strong hyaluronan expression in the full-thickness rat articular cartilage repair tissue. Histochem Cell Biol 2001;115:301-8.

51. Skaalure SC, Dimson SO, Pennington AM, Bryant SJ. Semiinterpenetrating networks of hyaluronic acid in degradable PEG hydrogels for cartilage tissue engineering. Acta Biomater
2014;10:3409-20.

52. Chung $\mathrm{C}$, Burdick JA. Influence of three-dimensional hyaluronic acid microenvironments on mesenchymal stem cell chondrogenesis. Tissue Eng Part A 2009;15:243-54.

53. Khademhosseini A, Eng G, Yeh J, Fukuda J, Langer R, Burdick JA. Micromolding of photocrosslinkable hyaluronic acid for cell encapsulation and entrapment. J Biomed Mater Res A 2006;79:522-32.

54. Mondalek FG, Ashley RA, Roth CC, Kibar Y, Shakir N, Ihnat MA, Fung KM, Grady BP, Kropp BP, Lin HK. Enhanced angiogenesis of modified porcine small intestinal submucosa with hyaluronic acid-poly(lactide-co-glycolide) nanoparticles: from fabrication to preclinical validation. J Biomed Mater Res A 2010;94:712-9.

55. Chen WH, Lo WC, Hsu WC, Wei HJ, Liu HY, Lee CH, Tina Chen SY, Shieh YH, Williams DF, Deng WP. Synergistic anabolic actions of hyaluronic acid and platelet-rich plasma on cartilage regeneration in osteoarthritis therapy. Biomaterials 2014;35:9599-607.

56. Frith JE, Menzies DJ, Cameron AR, Ghosh P, Whitehead DL, Gronthos S, Zannettino AC, Cooper-White JJ. Effects of bound versus soluble pentosan polysulphate in PEG/HA-based hydrogels tailored for intervertebral disc regeneration. Biomaterials 2014;35:1150-62.

57. Kim YM, Oh SH, Choi JS, Lee S, Ra JC, Lee JH, Lim JY. Adiposederived stem cell-containing hyaluronic acid/alginate hydrogel improves vocal fold wound healing. Laryngoscope 2014;124:E64-72.

58. Chen YC, Su WY, Yang SH, Gefen A, Lin FH. In situ forming hydrogels composed of oxidized high molecular weight hyaluronic acid and gelatin for nucleus pulposus regeneration. Acta Biomater 2013;9:5181-93.

59. Patterson J, Siew R, Herring SW, Lin AS, Guldberg R, Stayton PS Hyaluronic acid hydrogels with controlled degradation properties for oriented bone regeneration. Biomaterials 2010;31:6772-81.

60. Park HJ, Jin Y, Shin J, Yang K, Lee C, Yang HS, Cho SW. Catecholfunctionalized hyaluronic acid hydrogels enhance angiogenesis and osteogenesis of human adipose-derived stem cells in critical tissue defects. Biomacromolecules 2016;17:1939-48.

61. Subramaniam S, Fang YH, Sivasubramanian S, Lin FH, Lin CP. Hydroxyapatite-calcium sulfate-hyaluronic acid composite encapsulated with collagenase as bone substitute for alveolar bone regeneration. Biomaterials 2016;74:99-108.

62. Zou L, Zou X, Chen L, Li H, Mygind T, Kassem M, Bünger C. Effect of hyaluronan on osteogenic differentiation of porcine bone marrow stromal cells in vitro. J Orthop Res 2008;26:713-20.

63. Zhu M, Lin S, Sun Y, Feng Q, Li G, Bian L. Hydrogels functionalized with $\mathrm{N}$-cadherin mimetic peptide enhance osteogenesis of hMSCs by emulating the osteogenic niche. Biomaterials 2016;77:44-52.

64. Oberlender SA, Tuan RS. Spatiotemporal profile of N-cadherin expression in the developing limb mesenchyme. Cell Adhes Commun 2009;2:521-37.

65. Mckay WF, Peckham SM, Badura JM. A comprehensive clinical review of recombinant human bone morphogenetic protein-2 (INFUSE Bone Graft). Int Orthop 2007;31:729-34.

66. Bhakta G, Lim ZX, Rai B, Lin T, Hui JH, Prestwich GD, van Wijnen AJ, Nurcombe V, Cool SM. The influence of collagen and hyaluronan matrices on the delivery and bioactivity of bone morphogenetic protein-2 and ectopic bone formation. Acta Biomater 2013;9:9098106.

67. Bhakta G, Rai B, Lim ZX, Hui JH, Stein GS, van Wijnen AJ, Nurcombe V, Prestwich GD, Cool SM. Hyaluronic acid-based hydrogels functionalized with heparin that support controlled release of bioactive BMP-2. Biomaterials 2012;33:6113-22.

68. El Ghalbzouri A, Commandeur S, Rietveld MH, Mulder AA, Willemze R. Replacement of animal-derived collagen matrix by human fibroblast-derived dermal matrix for human skin equivalent 
products. Biomaterials 2009;30:71-8.

69. Stark H, Boehnke K, Mirancea N, Willhauck MJ, Pavesio A, Fusenig NE, Boukamp P. Epidermal homeostasis in long-term scaffoldenforced skin equivalents. J Investig Dermatol Symp Proc 2006;11:93-
105.

70. Alghoul M, Mendiola A, Seth R, Rubin BP, Zins JE, Calabro A, Siemionow M, Kusuma S. The effect of hyaluronan hydrogel on fat graft survival. Aesthet Surg J 2012;32:622-33. 